Published on Web 07/16/2005

\title{
Tunable Command Layers for Liquid Crystal Alignment
}

\author{
Johan Hoogboom, ${ }^{\dagger}$ Paula M. L. Garcia, Matthijs B. J. Otten, \\ Johannes A. A. W. Elemans, Joseph Sly, Sergiy V. Lazarenko, Theo Rasing, \\ Alan E. Rowan, and Roeland J. M. Nolte* \\ Contribution from the Institute for Molecules and Materials, Radboud University Nijmegen, \\ Toernooiveld 1, 6525ED Nijmegen, The Netherlands \\ Received March 23, 2005; E-mail: r.nolte@science.ru.nl
}

\begin{abstract}
A simple method for the construction of a stable, tunable, self-assembled command layer for liquid crystal display purposes is described. A pyridine-functionalized oligosiloxane spontaneously forms an anisotropic, grooved surface on indium-tin-oxide, enabling it to align liquid crystalline molecules. The pyridine functions act as seeds for the epitaxial growth of stacks of highly ordered zinc phthalocyanines, the height of which can be controlled. These stacks increase the interaction between the surface and the liquid crystalline matrix by amplifying the surface ordering into the liquid crystal bulk. By varying the height of the stacks, direct control over the properties of the liquid crystal domains is achieved. These properties can be further tuned by adding to the liquid crystal, micro- and nanomolar concentrations of nitrogencontaining compounds, which are capable of interacting with and dissolving the stacks. The procedures we describe offer possibilities to use such tunable systems in LCD-based sensor devices as well as in solar-cell applications.
\end{abstract}

\section{Introduction}

Uniform alignment of liquid crystal domains is usually achieved by rubbing a spin-coated polymer with a velvet cloth, a process which has been applied by industry for many years. ${ }^{1-3}$ This rubbing can create microscopic grooves and/or an anisotropic distribution of molecular bonds, in this way forming an anisotropic surface on which the nematogenic molecules align themselves, thereby minimizing the surface energy. ${ }^{3,4}$ In the past decade, several new methods for liquid crystal alignment have been introduced, ${ }^{3-7}$ e.g. photoinduced alignment ${ }^{5,6}$ and magnetic field alignment. ${ }^{7}$ Despite this, the attainment of direct and rational control over the molecular makeup of the alignment layer and its interaction with liquid crystalline molecules still poses a challenge.

We recently described a procedure for the preparation of stable, self-assembled alignment layers, ${ }^{8}$ which makes use of parallel nanometer-sized grooves that are present on commonly used indium-tin-oxide (ITO) surfaces. The size of these socalled "nanogrooves" is amplified over 3 orders of magnitude

Current address: Massachusetts Institute of Technology, 77 Massachusetts Avenue, Bldg. 18-143, Cambridge, MA 02139.

(1) Van Haaren, J. Nature 2001, 29, 411.

(2) Zöcher, H. Naturwissenschaften 1925, 13, 1015-1021

(3) Rasing, Th., Muševič, I., Eds. "Surfaces and Interfaces of Liquid Crystals", Springer: Heidelberg, 2004.

(4) Stöhr, J.; Samant, M. G.; Lüning, J.; Callegari, A. C.; Chaudhari, P.; Doyle, J. P.; Lacey, J. A.; Lien, S. A.; Purushothaman, S.; Speidell, J. L. Science 2001, 292, 2299-2302.

(5) Ichimura, K. Chem. Rev. 2000, 100, 1847-1874.

(6) Schadt, M.; Seiberle, H.; Schuster, A. Nature 1996, 381, 212-215.

(7) Boamfa, M. I.; Kim, M. W.; Maan, J. C.; Rasing, T. Nature 2003, 421, $149-152$

(8) Hoogboom, J.; Behdani, M.; Elemans, J. A. A. W.; Devillers, M. A. C.; De Gelder, R.; Rowan, A. E.; Rasing, T.; Nolte, R. J. M. Angew. Chem., Int. Ed. 2003, 42, 1812-1815.

10.1021/ja051865I CCC: $\$ 30.25$ ๑ 2005 American Chemical Society
Chart 1

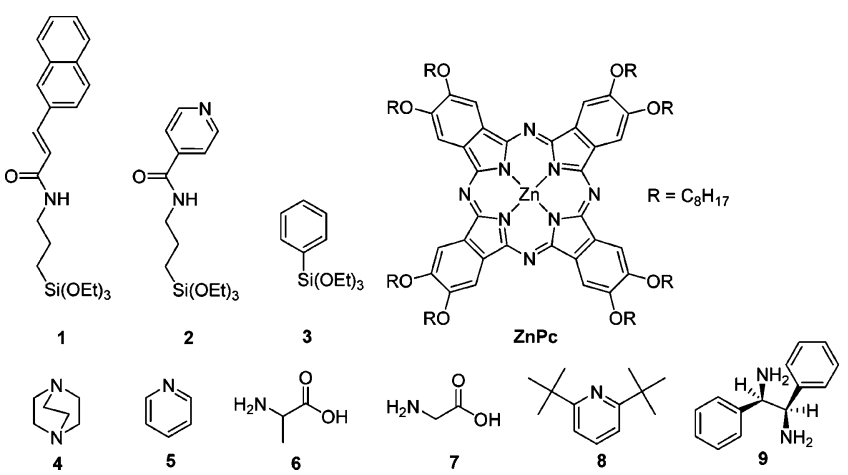

by the anisotropic grafting of monomer 1 (Chart 1), which spontaneously forms rigid oligomers in situ that self-assemble during layer formation to give aligned grooves of surface-grafted siloxane oligomers (Figure 1). When used in a twisted-nematic liquid crystal display (LCD), these self-assembled surfaces rivaled industrially manufactured displays in terms of interaction energy between the alignment layer and the liquid crystalline matrix.

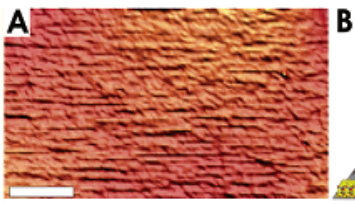

B

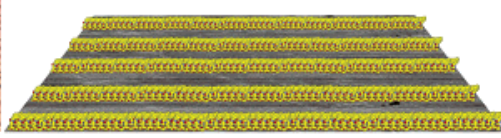

Figure 1. (A) AFM micrograph of a spontaneously formed alignment layer from $\mathbf{1} \cdot$ Bar is $1 \mu \mathrm{m}$. (B) Schematic representation of the molecular order in the alignment layer shown in (A); the aligned siloxane oligomers are indicated in yellow.

J. AM. CHEM. SOC. 2005, 127, 11047-11052

11047 
Scheme 1. Synthesis of 2

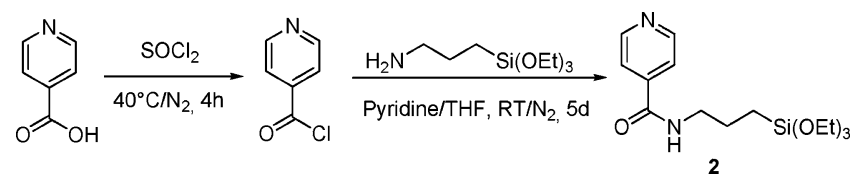

In this paper, we report on a modification of this procedure by including the pyridine-functionalized siloxane 2 (Chart 1), which results in the formation of an alignment layer with micrometer-sized grooves that is capable of binding the metalated dye zinc-phthalocyanine, $\mathrm{ZnPc}$ (Chart 1), by coordination of the pyridine functions to the zinc centers. This coordination initiates the surface-templated epitaxial growth of perpendicular stacks of highly ordered $\mathrm{ZnPc}$, the height of which can be controlled by varying the immersion time of the layer into a solution of ZnPc. In turn, this controlled molecular makeup of the alignment layer allows for rational control over its interaction properties with mesogens, leading to tunable anchoring energies. Moreover, the properties of the alignment layer can be further tuned by adding to the liquid crystalline matrix of a display after its construction, compounds that are capable of interacting with the stacks of dyes (nitrogen ligands 4-9).

\section{Experimental Methods ${ }^{9}$}

2.1. Synthesis. Unless stated otherwise, all reactions were carried out under Schlenk conditions in a nitrogen atmosphere. Toluene, THF, and hexane were distilled from sodium/benzophenone prior to use. Pyridine was distilled from $\mathrm{CaH}_{2}$. Thionyl chloride was distilled under reduced pressure. Zinc 2,3,9,10,16,17,23,24-octakis(octyloxy)-29H,31Hphthalocyanine $(\mathrm{ZnPc})$ was purchased from Aldrich and purified by column chromatography (eluent $2 \% \mathrm{MeOH} / \mathrm{CHCl}_{3} \mathrm{v} / \mathrm{v}$ ) before use. Triethoxy(phenyl)silane (3) was purchased from Aldrich and was distilled prior to use. All other chemicals were used without any further purification. Melting points were determined on a Jeneval polarization microscope THMS 600 hot stage and are uncorrected. ${ }^{1} \mathrm{H}$ NMR and ${ }^{13} \mathrm{C}\left\{{ }^{1} \mathrm{H}\right\}$ NMR spectra were recorded on a Bruker AM-300 instrument. Chemical shifts are reported in ppm downfield from internal $\left(\mathrm{CH}_{3}\right)_{4} \mathrm{Si}$ $(0.00 \mathrm{ppm})$. In the case of the ${ }^{13} \mathrm{C}$ spectra, the solvent peak was used as a reference $\left(\mathrm{CDCl}_{3}: 77.7 \mathrm{ppm}\right)$. Abbreviations used are: $\mathrm{s}=$ singlet, $\mathrm{d}=$ doublet, $\mathrm{dd}=$ doublet of doublets, $\mathrm{m}=$ multiplet, $\mathrm{br}=$ broad. EI mass spectra were recorded on a VG-7070E instrument. MALDI-TOF spectra were measured on a Bruker Biflex III spectrometer using dithranol as matrix.

$N$-4-[3-(1,1,1-Triethoxysilyl)propyl]isonicotinamide (2). The pyridine-functionalized siloxane 2 was synthesized in a two-step reaction (Scheme 1). Isonicotinic acid $(0.5 \mathrm{~g} ; 4.1 \mathrm{mmol})$ was converted into the acid chloride by stirring with $10 \mathrm{~mL}$ of thionyl chloride at $40{ }^{\circ} \mathrm{C}$ for $3 \mathrm{~h}$. The product was precipitated with $10 \mathrm{~mL}$ of hexane and washed three times with $10 \mathrm{~mL}$ of cold hexane. The white product was suspended in $50 \mathrm{~mL}$ of THF, after which $0.95 \mathrm{~mL}(4.1 \mathrm{mmol})$ of 3 -(1,1,1-triethoxysilyl)-1-propanamine in $20 \mathrm{~mL}$ of pyridine was added dropwise at room temperature. After 5 days stirring, the reaction mixture was filtered and evaporated to dryness, yielding a yellow oil. Extracting the oil with $50 \mathrm{~mL}$ of hexane:chloroform $(1: 1 \mathrm{v} / \mathrm{v})$ yielded a white suspension, which was evaporated to dryness to give a colorless liquid. Repeated recrystallizations from hexane yielded compound $\mathbf{2}$ in $60 \%$ overall yield. Due to its extreme water sensitivity, $\mathbf{2}$ was stored in anhydrous ethanol at $-20{ }^{\circ} \mathrm{C}$. If possible, analyses were performed under nitrogen and within 5 min after isolation of 2 from the mother solution. ${ }^{1} \mathrm{H}$ NMR $\left(300 \mathrm{MHz}, \mathrm{CDCl}_{3}, 20{ }^{\circ} \mathrm{C}\right.$, TMS $): \delta=8.70\left(\mathrm{dd}, J^{1}\right.$ $\left.=4.4 \mathrm{~Hz}, J^{2}=1.8 \mathrm{~Hz}, 2 \mathrm{H}, \mathrm{Py}-\mathrm{H}_{2,6}\right) ; 7.59\left(\mathrm{dd}, J^{1}=4.4 \mathrm{~Hz}, J^{2}=1.8\right.$ $\left.\mathrm{Hz}, 2 \mathrm{H}, \mathrm{Py}-\mathrm{H}_{3,5}\right) ; 6.71$ (s, br, 1H, NH); 3.82 (q, $J=6.9 \mathrm{~Hz}, 6 \mathrm{H}$,

(9) See Supporting Information for further details.
$\left.\mathrm{OCH}_{2} \mathrm{CH}_{3}\right) ; 3.47\left(\mathrm{~m}, 2 \mathrm{H}, \mathrm{NHCH}_{2}\right) ; 1.77$ (m, $\left.2 \mathrm{H}, \mathrm{NHCH}_{2} \mathrm{CH}_{2}\right) ; 1.22$ $\left(\mathrm{t}, J=6.9 \mathrm{~Hz}, 9 \mathrm{H}, \mathrm{CH}_{3}\right) ; 0.72\left(\mathrm{t}, J=7.8 \mathrm{~Hz}, 2 \mathrm{H}, \mathrm{Si}-\mathrm{CH}_{2}\right) .{ }^{13} \mathrm{C}\left\{{ }^{1} \mathrm{H}\right\}$ NMR (75 MHz, $\mathrm{CDCl}_{3}, 20^{\circ} \mathrm{C}$, TMS): $\delta=166.8$ (s, 1C, C=O); 153.5 (s, 2C, Py-C ${ }_{2,6}$ ); 141.3 (s, 1C, ipso-Py-C ${ }_{4}$ ); 123.9 (s, 2C, Py- $\mathrm{C}_{3,5}$ ); 61.9 (s, 3C, $\left.\mathrm{OCH}_{2}\right) ; 45.54$ (s, $\left.1 \mathrm{C}, \mathrm{NHCH}_{2}\right) ; 26.1$ (s, 1C, $\left.\mathrm{NHCH}_{2} \mathrm{CH}_{2}\right) ; 21.7$ (s, 3C, $\left.\mathrm{CH}_{3}\right) ; 11.4$ (s, $\left.1 \mathrm{C}, \mathrm{Si}-\mathrm{CH}_{2}\right) . \mathrm{Mp}\left({ }^{\circ} \mathrm{C}\right)$ : 4 (uncorrected). EI-MS: $m / z(\%) 326(2.5)\left[\mathrm{M}^{+}\right] ; 297(13.0)[\mathrm{M}-\mathrm{Et}]^{+} ; 280(90.0)[\mathrm{M}$ $-\mathrm{HOEt}]^{+}$; 265 (8.4) $\left[\mathrm{M}-\mathrm{OEt}-\mathrm{CH}_{3}\right]^{+}$; 251 (9.7) [M - OEt $\mathrm{Et}]^{+} ; 208$ (12.3) $[\mathrm{M}+\mathrm{H}-2 \mathrm{OEt}-\mathrm{Et}]^{+} ; 189$ (11.9) $\left.[\mathrm{M}-3 \mathrm{OEt})\right]^{+}$; $175(13.5)\left[(\mathrm{EtO})_{3} \mathrm{SiC}\right]^{+} ; 163(100.0)\left[\mathrm{Si}(\mathrm{OEt})_{3}\right]^{+}$or $\left[\mathrm{PyCONH}\left(\mathrm{CH}_{2}\right)_{3}\right]^{+}$; 135 (27.4) $\left[\mathrm{Py}-\mathrm{CONHCH}_{2}\right]^{+} ; 123$ (28.1) $\left[\mathrm{Py}-\mathrm{CONH}_{3}\right]^{+} ; 119$ (36.4) $\left[\mathrm{HSi}(\mathrm{OEt})_{2}\right]^{+} ; 106(41.0)[\mathrm{Py}-\mathrm{CO}]^{+} ; 78(44.1)[\mathrm{Py}]^{+}$. Due to the extreme water sensitivity of $\mathbf{2}$, no elemental analysis or infrared spectrum could be obtained. High-resolution-EI-MS: Found: 326.16619, calculated for $\mathrm{C}_{15} \mathrm{H}_{26} \mathrm{~N}_{2} \mathrm{O}_{4} \mathrm{Si}$ : 326.1662 .

Zinc 2,3,9,10,16,17,23,24-Octakis(octyloxy)-29H,31H-phthalocyanine (ZnPc): UV/vis spectroscopy: $\lambda_{\max }(\mathrm{nm})\left(\mathrm{CHCl}_{3}\right)=345(\log \epsilon$ = 4.87), 385 (4.44), 427 (4.41), 618 (4.60), 652 (4.67), 682 (5.34). MALDI-TOF: $\mathrm{M}^{+}=1603.6$

2.2. Physical Methods. A Nanoscope III and a Dimension 3000 atomic force microscope (Digital Instruments, Veeco Metrology Group 112 Robin Hill Road, Santa Barbara, CA 93117), with standard silicon nitride tips were used to scan the substrates. The ITO used in these experiments was purchased from the Applied Film Corporation (6797 Winchester Circle, Boulder, CO 80301). The exact manufacturing process is unknown to us. Ellipsometry measurements indicated that the ITO plates consisted of $20 \mathrm{~nm}$ ITO coated by rf sputtering over a roughened polycrystalline $\mathrm{SiO}_{2}$ layer $(20 \mathrm{~nm})$ on a $1.1 \mathrm{~mm}$ sodalime glass substrate (BK7). The ITO layer was polished by the manufacturer to obtain optical quality for LCD application. ITO plates were cleaned with ozone $(100 \mathrm{~L} / \mathrm{h})$ for $3 \mathrm{~h}$ prior to use. Alignment layers were prepared by immersion of an ITO plate into a solution of $\mathbf{2 / 3}$ in toluene-ethanol ( $2 \mathrm{vol} \%$ ethanol) containing a drop of acetic acid to activate the surface. The molar ratio of $\mathbf{2 : 3}$ was $1: 9$, at a total siloxane concentration of $0.5 \mathrm{wt} \%$. After $60 \mathrm{~min}$, the plate was taken out, washed with acetonitrile, and baked in an oven at $120^{\circ} \mathrm{C}$ for $10 \mathrm{~min}$ to complete covalent bonding of the siloxanes to the ITO, as well as to remove any residual solvent.

$\mathrm{ZnPc}$ alignment layers were constructed by immersing these pyridinecontaining ITO plates into a 7.1 $\mu \mathrm{M}$ chloroform solution of ZnPc. After a fixed period of time, the plate was removed and rinsed with chloroform, after which it was dried in ambient conditions.

Polarized Fourier transform infra-red (FTIR) spectra were recorded on a BioRad FTS-25 spectrometer at $2 \mathrm{~cm}^{-1}$ resolution using a goldsputtered ruby polarizer. FTIR experiments were performed at normal incidence to the ITO surface. The ordering of the alkyl tails of the $\mathrm{ZnPc}$ stacks was studied by using their $\mathrm{CH}$-stretching vibrations at 2923 $\mathrm{cm}^{-1}$ as spectator vibrations. The order parameter, $S$, and the average tilt angle of the aromatic rings of the phthalocyanine dye molecules with respect to the surface, $\Psi$, were calculated from measurements using the in-plane $\mathrm{CH}$-stretching vibration of the core at $3019 \mathrm{~cm}^{-1}$ as a spectator vibration. ${ }^{9-12}$ The layered structure of the ITO plate interfered with $\mathrm{UV}$-vis measurements at the low surface concentration of $\mathrm{ZnPc}$ due to scattering effects, leaving only FTIR as spectroscopic tool to investigate the plates, which also exhibited an IR-cutoff below $2100 \mathrm{~cm}^{-1}$.

Shear force was applied by unidirectionally rinsing the plates with the $\mathrm{ZnPc}$ stacks with $2 \mathrm{~mL}$ of chloroform using a Pasteur pipet, after which the plate was dried in a nitrogen flow in the same direction as the rinsing. Anchoring energies were determined by the cell-rotation method, using a standard twisted-nematic cell (vide infra), with a

(10) Sauer, T.; Arndt, T.; Batchelder, D. N.; Kalachev, A. A.; Wegner, G. Thin Solid Films 1990, 187, 357-374.

(11) Smolenyak, P.; Peterson, R.; Nebesny, K.; Törker, M.; O'Brien, D. F. Armstrong, N. R. J. Am. Chem. Soc. 1999, 121, 8628-8636.

(12) Smolenyak, P. E., Peterson, R. A., O'Brien, D. F., Armstrong, N. L. Eds. Porphyrins and Phthalocyanines; Wiley: West Sussex, 2000. 


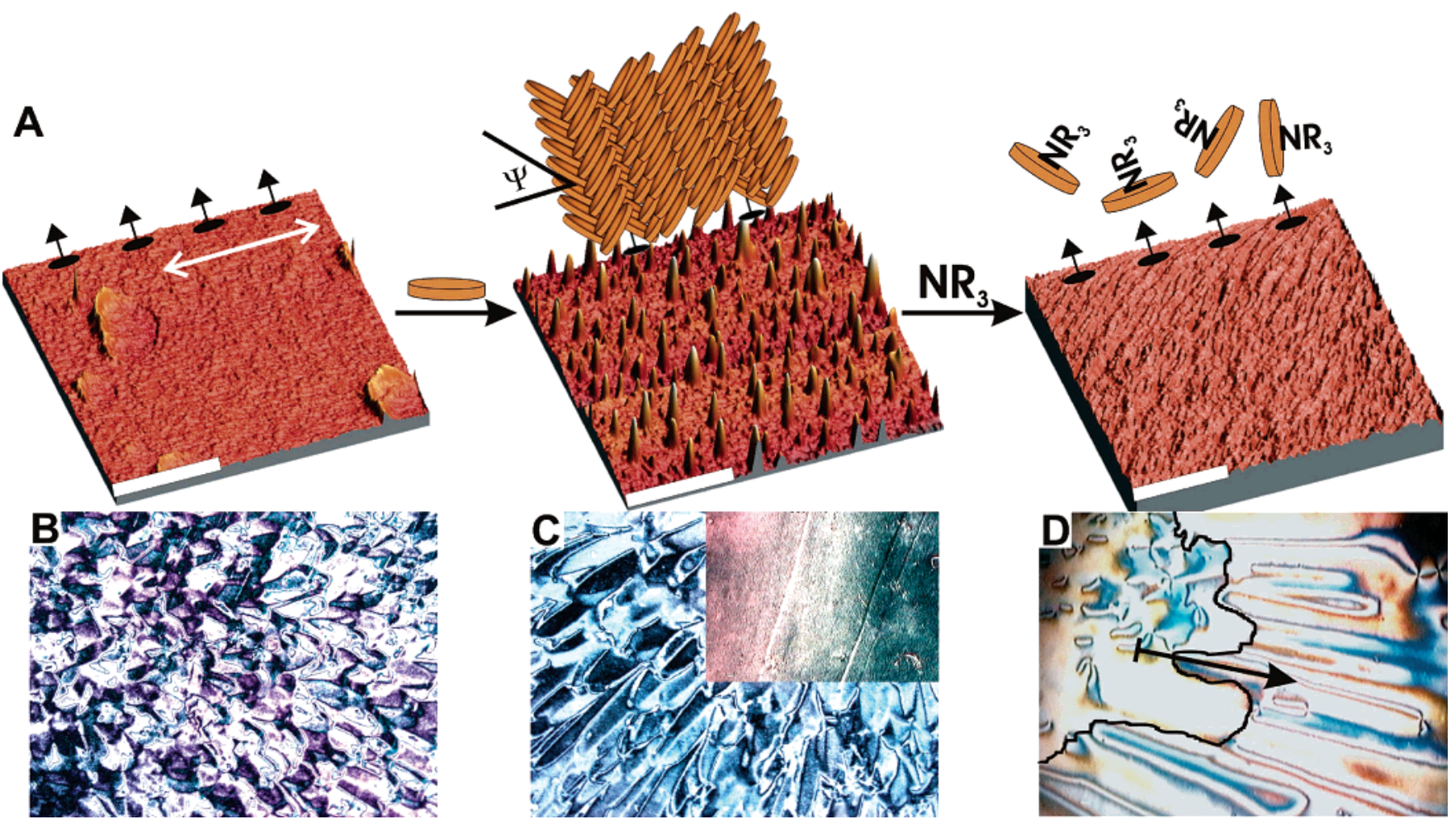

Figure 2. (A) Schematic depiction of the epitaxial growth of ZnPc stacks, templated by an alignment layer formed from $\mathbf{2}$ and $\mathbf{3}$, followed by the disruption of the aggregates by the addition of nitrogen-containing compounds. The direction of the surface grooves is indicated by the white arrow, pyridine binding sites are depicted as black arrows, maximum peak height is $55 \mathrm{~nm}$, the tilt angle of the $\mathrm{ZnPc}$ molecules is indicated by $\Psi$. All bars are $1 \mu \mathrm{m}$. (B-D) Polarizing micrographs of parallel liquid crystal cells with an unrubbed polyimide counterplate and a sample plate constructed using: (B) a spontaneously formed layer from $\mathbf{2}$ and $\mathbf{3}$ and (C) a layer with ZnPc stacks. (Inset) Liquid crystal texture after application of a shear flow. (D) Layer with ZnPc stacks during infusion of 4 in the direction of the arrow. The line is a guide to the eye. All polarizers at $45^{\circ}$, images are $600 \mu \mathrm{m} \times 400 \mu \mathrm{m}$, except the inset, which is $6 \mathrm{~mm} \times 4 \mathrm{~mm}$.

conventionally rubbed polyimide plate as a counter plate. ${ }^{9,13-19}$ In the case of the $\mathrm{ZnPc}$ alignment layers, plates with shear-induced alignment were used in anchoring energy measurements. Other LCDs were prepared by using one sample plate and a counter plate which was spin coated with Polyimide Pyralin PI2555 (HD Microsystems) at 5000 rpm for $20 \mathrm{~s}$ and baked at $120^{\circ} \mathrm{C}$ for $90 \mathrm{~min}$. Mylar spacers of $6 \mu \mathrm{m}$ were used to separate the plates. ${ }^{8,17,19}$ LCDs were filled with 4-n-pentyl$4^{\prime}$-cyanobiphenyl $(5 \mathrm{CB})$ in the isotropic phase at $40{ }^{\circ} \mathrm{C}\left(T_{\mathrm{NI}}=35.3\right.$ ${ }^{\circ} \mathrm{C}$ ) and were submitted to a heating-cooling cycle between 20 and $40{ }^{\circ} \mathrm{C}$ three times to exclude any memory effects. ${ }^{8,19}$ Solutions of nitrogen-containing compounds in $5 \mathrm{CB}$ were pulled into the liquid crystal cell via capillary force in $15 \mathrm{~min}$. The concentrations used were as follows: 4 in $5.9 \mathrm{mM}$ and $14 \mu \mathrm{M}, 5$ in $61 \mu \mathrm{M}$ and $139 \mathrm{nM}, \mathbf{6}$ and 7 in $4 \mu \mathrm{M}$ and 8 and 9 in $4 \mathrm{mM}$.

\section{Results and Discussion}

3.1. Physical Characterization of Alignment Surfaces. Pyridine-containing alignment layers were constructed by immersing an ITO plate into a solution of $\mathbf{2}$ and $\mathbf{3}$ in toluene. When these ITO plates were examined with atomic force microscopy (AFM), a surface containing micrometer-sized grooves was observed, resembling those previously reported by us (Figure

(13) Ryan-Brown, G. P.; Sage, I. C. Liq. Cryst. 1996, 20, 825-829.

(14) Kim, M. W.; Rastegar, A.; Drevenšek Olenik, I.; Rasing, T. J. Appl. Phys. 2001, 90, 3332-3337.

(15) Newsome, C. J.; O’Neill, M.; Farley, R. J.; Bryan-Brown, G. P. Appl. Phys. Lett. 1998, 72, 2078-2080.

(16) Lu, X.; Lu, Q.; Zhu, Z. Liq. Cryst. 2003, 30, 985-990.

(17) Behdani, M.; Keshmiri, S. H.; Soria, S.; Bader, M. A.; Ihlemann, J.; Marowsky, G.; Rasing, T. Appl. Phys. Lett. 2003, 82, 2553-2555.

(18) Berreman, D. W. Phys. Rev. Lett. 1972, 28, 1683-1686.

(19) Rastegar, A.; Skarabot, M.; Blij, B.; Rasing, T. J. Appl. Phys. 2001, 89, 960-964.
2A). ${ }^{8,9}$ After this layer was reacted with a $7.1 \mu \mathrm{M}$ chloroform solution of $\mathrm{ZnPc}$ for $3 \mathrm{~h}$, AFM studies revealed the presence of large objects on the surface with a height of ca. $50 \mathrm{~nm}$ (Figure 2A), which we attribute to the presence of stacks of aggregated $\mathrm{ZnPc}$ molecules. ${ }^{20}$ The height of the stacks could be controlled by varying the immersion time of the ITO plate into the $\mathrm{ZnPc}$ solution. The maximum height increased from $25 \mathrm{~nm}$ after 30 min to $50 \mathrm{~nm}$ after 3 h. ${ }^{9}$ Longer immersion times did not yield higher stacks, suggesting that they are in thermodynamic equilibrium with $\mathrm{ZnPc}$ in solution. As the critical aggregation concentration of $\mathrm{ZnPc}$ was determined to be at least 3 orders of magnitude higher than the concentration used in this experiment, ${ }^{9}$ these results imply that the coordination of single molecules of $\mathrm{ZnPc}$ from solution to the pyridine functions in the alignment layer results in the surface-templated growth of stacks, which, to our knowledge, is unprecedented for phthalocyanines. ${ }^{21}$

$\mathrm{UV}$-vis experiments clearly showed that $\mathbf{2}$ coordinates to ZnPc. ${ }^{9}$ To investigate whether the binding of $\mathrm{ZnPc}$ to the surface could be attributed to interactions other than coordination, e.g. van der Waals forces or $\pi-\pi$-interactions, an ITO plate was covered with only 3 from the vapor phase and reacted with a $7.1 \mu \mathrm{M}$ solution of $\mathrm{ZnPc}$ for $3 \mathrm{~h}$, followed by washing with chloroform. AFM and FTIR confirmed the absence of ZnPc

(20) Van der Pol, J. F.; Neeleman, E.; Zwikker, J. W.; Nolte, R. J. M.; Drenth, W. Recl. Trav. Chim. Pays-Bas 1988, 107, 615-620.

(21) The formation of aggregates of large, extended porphyrin systems has been reported before by Drain et al.: Drain, C. M.; Batteas, J. D.; Flynn, G. W.; Milic, T.; Chi, N.; Yablon, D. G.; Sommers, H. Proc. Natl. Acad. Sci. U.S.A. 2002, 99, 6498-6502. 

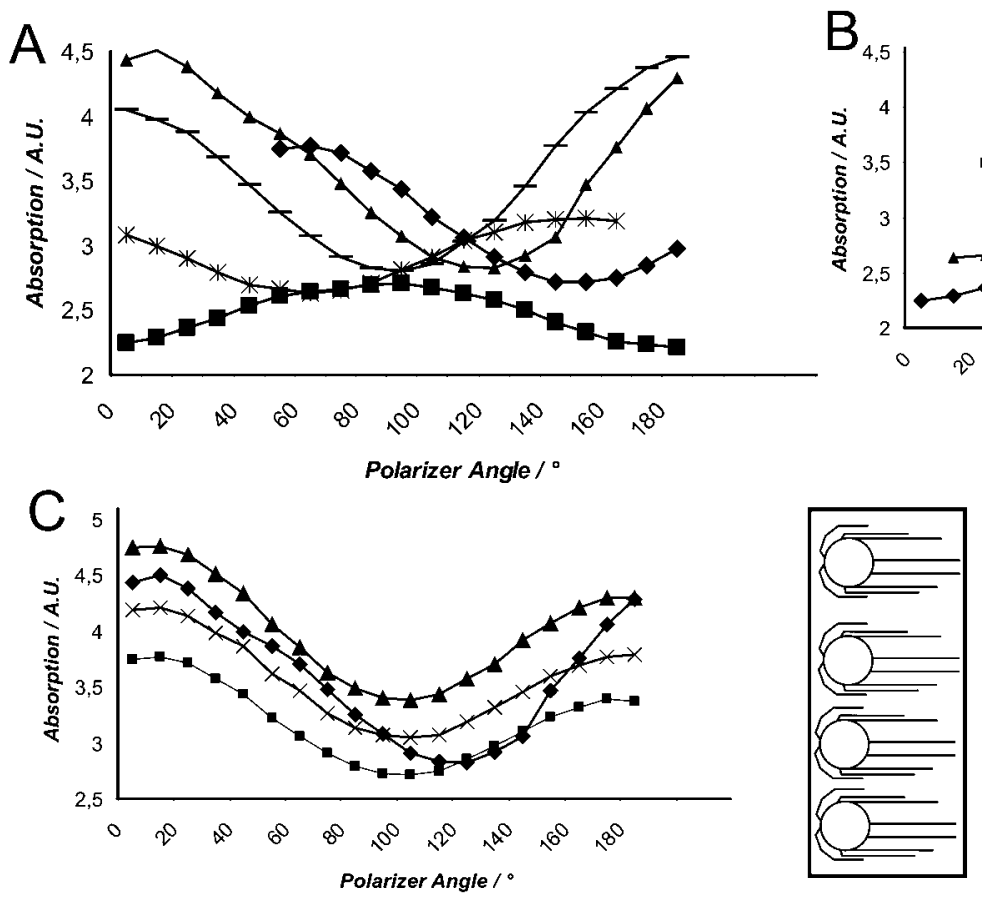
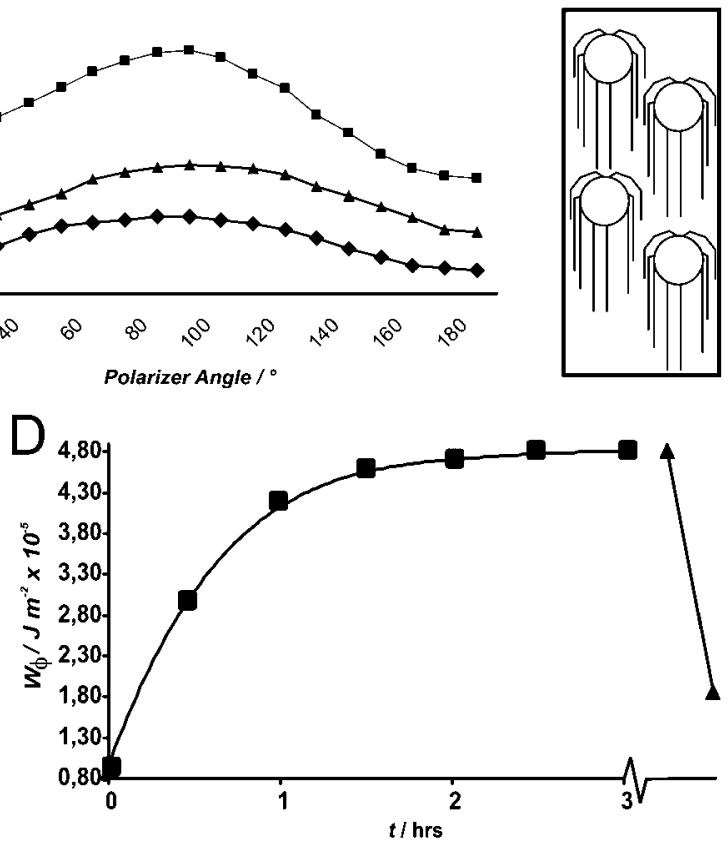

Figure 3. (A-C): Plots of the intensity of the aliphatic stretching vibrations of $\mathrm{ZnPc}$ aggregates, as a function of polarizer angle. (A) Without an applied shear flow. (B) With a shear flow applied in the direction of the long axis of the plate. (Inset) Schematic top view of ZnPc stacks showing a possible conformation of the alkyl tails. (C) With a shear flow applied in the direction of the short axis of the plate. (Inset) Schematic top view of ZnPc stacks showing a possible conformation of the alkyl tails. Each curve was measured at a different spot on the same ITO plate. (D) Plot of the anchoring energy of a cell with an alignment layer prepared from $\mathbf{2}$ and $\mathbf{3}$, containing $\mathrm{ZnPc}$ stacks, as a function of the immersion time of the layer into a solution of ZnPc. The triangles indicate the effect of the introduction of $139 \mathrm{nM}$ of $\mathbf{5}$. The line is a guide to the eye.

(stacks) on the surface. Furthermore, experiments showed that under the same experimental conditions, the free-base phthalocyanine did not form aggregates on the pyridine-containing alignment layer and was rinsed off completely with chloroform. These experiments support the idea that coordinative binding of the phthalocyanine is required.

The width of the objects did not display a time dependence. It varied between 25 and $190 \mathrm{~nm}$, which is too large for a single ZnPc stack. Although this width can be partially attributed to AFM-tip effects, it is very likely that a cluster of $\mathrm{ZnPc}$ stacks is present, which is anchored to the surface by several pyridine functionalities and held together by van der Waals interactions between adjacent ZnPc stacks (schematically depicted in Figure $2 \mathrm{~A})$. The aspect ratio (h/w, as calculated by AFM) of the stacks after $3 \mathrm{~h}$ of immersion supports this notion, as it varies from 0.21 to 0.53 for stacks between 45 and $55 \mathrm{~nm}$ in height, suggesting the presence of multiple stack types. Aggregation of this type has been observed before by us for similar dye systems, albeit not epitaxially templated by a surface..$^{20,22,23}$ The distribution of the number of $\mathrm{ZnPc}$ aggregates after $3 \mathrm{~h}$ of immersion was not constant over the area of the ITO plate, which measured $10 \mathrm{~mm} \times 15 \mathrm{~mm}$. It ranged from 13 to 31 stacks per $\mu \mathrm{m}^{2}$, with an average of 20 stacks per $\mu \mathrm{m}^{2}$, measured over 4 AFM micrographs with a total surface area of $60 \mu \mathrm{m}^{2}$. Assuming that a stack of $50 \mathrm{~nm}$ contains about $150 \mathrm{ZnPc}$ molecules, ${ }^{20}$ these results imply a ballpark figure for the surface coverage of $\mathrm{ZnPc}$ of $10^{11}$ molecules per $\mathrm{cm}^{2}$, or $10^{-13}$ mol per $\mathrm{cm}^{2}$.

(22) Engelkamp, H.; Middelbeek, S.; Nolte, R. J. M. Science 1999, 284, 785788 .

(23) De la Escosura, A.; Martínez-Díaz, M. V.; Thordarson, P.; Rowan, A. E.; Nolte, R. J. M.; Torres, T. J. Am. Chem. Soc. 2003, 125, 12300-12308.
Polarized FTIR measurements on the $\mathrm{CH}$-stretching vibrations of the alkyl tails of the stacks showed that their ordering is clustered in rather large domains of several hundred square micrometers but that the domain orientations differ from place to place on the surface, as indicated by a phase shift in their respective polarization angle-dependent absorption curves (Figure 3A). Remarkably, FTIR measurements showed that the application of a shear force, i.e., the unidirectional rinsing of the plates with chloroform, caused this phase shift to disappear, indicating a similar orientation of the alkyl tails over the entire sample plate (Figure 3B,C), offering a second degree of control over the surface ordering. From these data, it is difficult to determine an absolute angular direction or conformation of the alkyl tails on the surface. However, the remarkable angle dependence of the absorption profiles suggest a (partial) rearrangement of the alkyl tails upon unidirectional rinsing. The FTIR experiments also provided information on the orientation of the phthalocyanine rings in the stacks. Both the order parameter, $S$, and the average tilt angle of the aromatic rings of the phthalocyanine dye molecules with respect to the surface, $\Psi$, can be calculated from the polarized FTIR measurements. ${ }^{9-12}$ From eight spots on one plate, an order parameter $S$ of $0.22 \pm$ 0.04 and an angle $\Psi$ of $51.4 \pm 1.1^{\circ}$ were calculated (the ordering is schematically depicted in Figure 2A). Interestingly, $S$ and $\Psi$ remained the same with or without application of shear force, which implies that rinsing had little effect on the angle between the aromatic plane of the $\mathrm{ZnPc}$ molecules in the stack and the surface and that the aggregates are firmly linked to the surface.

3.2. Effects on Liquid Crystal Alignment. When the alignment layer, prepared by the deposition of $\mathbf{2}$ and $\mathbf{3}$ but without exposure to the $\mathrm{ZnPc}$ solution, was used in the 
construction of a parallel liquid crystal cell with $5 \mathrm{CB}$ as the mesogen, alignment of the mesogen due to the groove structure was observed with domain sizes in the order of several tens of micrometers (Figure 2B). Remarkably, when the plates containing the tallest $\mathrm{ZnPc}$ stacks were tested, the domain size increased to hundreds of micrometers, indicating that the alignment capability had increased as a result of the presence of the stacks (Figure 2C). The directors of the liquid crystal domains were not uniformly aligned, which can be attributed to the clustering of the alkyl tails of the ZnPc stacks, causing adjacent domains to be oriented differently, which was supported by the polarized FTIR experiments (vide supra). However, when the alignment surfaces that had been subjected to a shear force were used in the construction of the liquid crystal cells, the domain boundaries of the liquid crystalline compound disappeared completely (Figure 2C, inset). This implies the formation of uniform alignment throughout the entire liquid crystal cell, extending over long distances up to $1.2 \mathrm{~cm}$, which was also supported by the FTIR experiments on the shear aligned surfaces (vide supra).

The enhanced alignment capability of the layer could be affected by introducing compounds into the cells that are capable of disturbing the stacks of dye molecules, e.g. nitrogen donor ligands 4 and 5 or amino acids 6 and 7 (Chart 1). By pulling micromolar concentrations of these ligands through the cells, a wave front was seen traversing the cell, leaving a nonaligning layer behind (Figure 2D). This effect is ascribed to the coordination of the nitrogen-containing molecules to the zinc metal centers in the dyes, ${ }^{24-26}$ followed by the dissolution of the stacks. AFM indicated that after the addition of the nitrogen donor compounds, the stacks of $\mathrm{ZnPc}$ on the surface had disappeared (Figure 2A), which was confirmed by FTIR which also revealed the presence of molecularly dissolved $\mathrm{ZnPc}$ in the mesogenic medium. To test the selectivity of the effect with respect to nitrogen-donor compounds, benzene, cyclohexanone, and toluene were pulled through liquid crystal cells in millimolar concentrations. Polarizing microscopy revealed that the quality of the liquid crystal alignment was not affected, supporting the notion that coordinative dissolution of the $\mathrm{ZnPc}$ stacks is responsible for the loss of liquid crystal alignment observed in the other experiments. Furthermore, 5CB itself, which is capable of coordinating metals with its cyano group and is present in a high concentration, did not influence the alignment quality, suggesting that only more strongly binding amines are capable of dissolving the $\mathrm{ZnPc}$ stacks. In addition, the introduction of the sterically hindered 2,6-di-tert-butylpyridine $\mathbf{8}$ in millimolar concentrations, which is not capable of coordinating to zinc and hence of disrupting the stacks, did not have any adverse effects on the alignment properties of the layer, further supporting the idea that the dissolution of $\mathrm{ZnPc}$ stacks from the surface is responsible for the loss of alignment quality. Remarkably, when the chiral bidentate amine $(1 R, 2 R)$-1,2-diphenylethane-1,2diamine 9 , in a concentration of $4 \mathrm{mM}$, was used to disrupt the uniform alignment of a shear-aligned cell, polarizing microscopy showed that a cholesteric liquid crystal phase was formed, embedded in a normal nematic phase (Figure 4). ${ }^{27}$ Blank

(24) Kasuga, K.; Asano, K.; Lin, L.; Sugimori, T.; Handa, M.; Abe, K.; Kikkawa, T.; Fujiwara, T. Bull. Chem. Soc. Jpn. 1997, 70, 1859-1865.

(25) Kaneko, Y.; Arai, T.; Tokumaru, K.; Matsunaga, D.; Sakuragi, H. Chem. Lett. 1996, 345-346.

(26) Moon, M.; Cheon, Y.; Kim, D. Photochem. Photobiol. 1993, 58, 31-35.

(27) Collings, P. J., Hird, M., Eds. Introduction to Liquid Crystals; Taylor \& Francis: London, 1998.

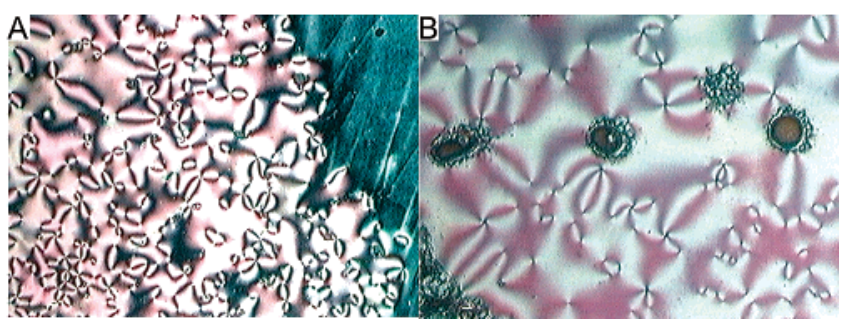

Figure 4. Polarizing micrographs of (A) Shear-aligned cell during infusion with 9. Residual alignment is visible in the top right corner. Image is 600 $\mu \mathrm{m} \times 400 \mu \mathrm{m}$. (B) Cholesteric droplets imbedded in the nematic phase. Image is $125 \mu \mathrm{m} \times 100 \mu \mathrm{m}$.

experiments indicated that 9 by itself is not capable of inducing a cholesteric phase inside 5CB. As such, the occurrence of this phase has to be ascribed to the coordination complex of $\mathbf{9}$ and $\mathrm{ZnPc}$. The $\mathrm{ZnPc}$ aggregates are not uniformly distributed over the surface, which implies that, immediately upon their dissolution, there are large local differences in the concentration of the coordination complex. It is therefore likely that the cholesteric droplets only appear in regions where enough $\mathrm{ZnPc}$ has been dissolved into the $5 \mathrm{CB}$. These experiments show that the $\mathrm{ZnPc}$-modified alignment layer can be easily influenced by even micromolar concentrations of nitrogen-donor ligands and respond distinctly upon the addition of a varying concentration of different amines.

These above-described effects were also reflected in the anchoring energy, which is a property of alignment layers that quantifies the interaction strength between the layer and the mesogenic molecules on top of it. ${ }^{8,9,13-19}$ For the alignment layer composed of $\mathbf{2}$ and $\mathbf{3}$ and using the common mesogen 5CB in the cell, this energy was measured to be $9.0 \times 10^{-6} \mathrm{~J} \mathrm{~m}^{-2}$. Upon immersion of the plate into the $\mathrm{ZnPc}$ dye solution, this value increased rapidly and leveled off at $4.8 \times 10^{-5} \mathrm{~J} \mathrm{~m}^{-2}$ (Figure 3D), showing that the anchoring energy, like the stack height, could be controlled by varying the immersion time. Furthermore, the final value of the anchoring energy is a factor of 2-3 higher than that reported for rubbed polyimide alignment layers currently employed by industry., ${ }^{3,19}$ The increase in anchoring is attributed to the superior molecular interaction of the $\mathrm{ZnPc}$ stacks with the bulk of the liquid crystal, compared to that of conventional alignment layers: the $\mathrm{ZnPc}$ stacks extend $50 \mathrm{~nm}$ into the bulk of the $5 \mathrm{CB}$, whereas in the case of a conventional alignment layer, only interaction with the first few layers of liquid crystalline molecules takes place. Experiments also indicated that the anchoring energy could be tuned. The addition of nitrogen-donor compounds 4-7 in micromolar concentrations induced a complete loss of anchoring (vide supra). Even the addition of nanomolar concentrations of these compounds had a strong effect. For instance, $\mathbf{4}$ gave a complete loss of anchoring energy upon addition in nanomolar concentrations, whereas 5 reduced it by a factor of 2.5 (Figure 3D). These combined results indicate that the properties of an alignment layer can be rationally manipulated.

\section{Conclusions}

In conclusion, we have presented a simple procedure for the construction of a stable and tunable alignment layer for mesogens, which is based on hierarchical assembly processes. The interaction of a spontaneously formed pyridine-containing 
alignment layer with single $\mathrm{ZnPc}$ dye molecules in solution results in the surface-templated growth of perpendicular stacks of which the size can be controlled by varying the immersion time. This control over the stack size is directly translated into control over the alignment properties of the alignment layer. Moreover, the introduction of compounds that interact with and destroy the stacks offers a second degree of control over the properties of the alignment layers, which have exhibited stability under ambient conditions for periods exceeding 18 months. The procedure presented here offers possibilities to develop very sensitive LCD-based sensor systems ${ }^{28-31}$ for the detection of, for example, proteins, nucleic acids, and other biomolecules that can bind to $\mathrm{ZnPc}$ stacks via nitrogen donor ligands, as well as

(28) Brake, J. M.; Daschner, M. K.; Luk, Y.-Y.; Abbott, N. L. Science 2003 302, 2094-2097.

(29) Luk, Y.-Y.; Tingey, M. L.; Dickson, K. A.; Raines, R. T.; Abbott, N. L. J. Am. Chem. Soc. 2004, 126, 9024-9032 and references therein.

(30) Yang, K.-L.; Cadwell, K.; Abbott, N. L. J. Phys. Chem. B 2004, 108, 20180-20186.

(31) Shah, R. R.; Abbott, N. L. Science 2001, 293, 1296-1299. systems that rely on ordered dye assemblies for optimal performance, such as photovoltaic devices. ${ }^{32}$

Acknowledgment. We thank R. G. E. Coumans, F. de Loos, P. Thomassen, and P. van Galen for experimental assistance, and Prof. D. J. Broer and Dr. J. J. L. M. Cornelissen for fruitful discussions. These studies were supported by the Dutch Technology Foundation (STW), Project Number NNS4857, and the European TMR Phthalocyanine Network (HPRN-CT-200000020).

Supporting Information Available: Oligomer characterization, additional physical characterization of the alignment layer and aggregates, spectral data on the binding of $\mathbf{2}$ to $\mathrm{ZnPc}$, and determination of the critical aggregation concentration of $\mathrm{ZnPc}$. This material is available free of charge via the Internet at http://pubs.acs.org.

JA051865L

(32) Schmidt-Mende, L.; Fechtenkötter, A.; Müllen, K.; Moons, E.; Friend, R. H.; MacKenzie, J. D. Science 2001, 293, 1119-1122. 